\title{
Impact of COVID-19 On Fintech Industry
}

\author{
Dakshata Nair ${ }^{1 *}$, Mounika Veeragandham ${ }^{2}$, Priya Pamnani ${ }^{3}$, Sumit Prasad $^{4}$, M. Guruprasad ${ }^{5}$ \\ 1,2,3,4,5 Department of PGDM, Universal Business School, Karjat, India
}

\begin{abstract}
This study is a part of our research project to get a brief insight on what changes and how the functioning of Fintech Industry has changed due to the impact of COVID-19 in India. The research paper talks about the sectors of fintech Industry and what reforms have been made that COVID-19 help the sector flourish post pandemic in India.
\end{abstract}

Keywords: Fintech, Technology, COVID-19, Customers, Key reforms.

\section{Introduction}

An extreme shift in finance, venture, trade, and digital money has been triggered by concerted efforts between accounting and innovation, and this is just the iceberg tip. The ubiquity of the word "Fintech" i.e., a short structure for the financial technology expression which was prompted by this growth.

Fintech is considerably more than merely a reference to innovation linked to finance. It is also referred to as the creative invention used to enhance customer money related techniques and build effective responses for budgetary administration those with the new mechanical trends that are normal. In monetary creativity banking programming and portable financial applications are excellent examples of progress. India now has a structure in place that offers a chance for new enterprises to grow exponentially into huge organizations, new Fintech firms are moving progress that has been considered difficult to make directly from digging into several unexplored pieces to outside market sectors.

COVID-19 has also caused disruption has affected each sector and disrupted its function, with Fintech industry being no exception. With most fintech firms grappling with shocks of COVID-19 pandemic, many firms are adopting new ways to tackle and save their business. It has led to shift in payments habit amidst the pandemic and has paved for artificial intelligence to replicate human touch for interaction regarding payments. While the sector conjures up images of start-ups and technology that is evolving in the market, conventional businesses and banks are still actively using fintech services for their own purposes. Leading Fintech.

Companies in India include Paytm, Policy Bazar, Zaggle, Mobikwick, Pine Labs etc.

\section{Research Methodology}

\section{A. Research Objectives}

The following are the objectives for investigation,
- To consider the growth and sectors of fintech in India.

- To analyse the fintech sectors in India.

- To evaluate and analyse the impact of COVID-19 on Fintech Industry in India.

- Study the strategies taken by Fintech Companies to compete in post COVID-19 world.

\section{B. Research Design}

- The investigation was done during COVID-19 19 pandemic that covers changes taking place in the Indian Fintech Sector.

- The research paper has been developed through secondary sources of data from dairy articles and other scholastic journals.

\section{Literature Review}

According to Anjan V. Thakor, fintech is the use of technology to carry out financial activities more effectively within a short span of time. The cost for the financial services has not altered. It remains $2 \%$ over the past 100 years. Productivity and mortgage lending has increased over the years. The three phases of Fintech are from: i) 1866 - 1967 (first transAtlantic cabled was layered and telegram started) ii) 1967 2008 (internet banking, ATM's \& electronic payments started) iii) 2008 - present (technological enhancement with increase in competition). (Thakor, 2019)

As per the survey conducted by Deloitte India, fintech companies in India is one among the top five markets whose value is 270 million dollars in 2016 by investing and capital funding. Fintech companies in India has potential to develop in many ways: i) Increase in fintech companies leads to costreduction and improvement in quality of services provided by them. ii) Many techniques are innovated till date and being inventing to assess the risk associated by fintech companies to underwrite credit score of customers based on credit history of customers. iii) fintech companies are unlike banks they offer more services which are efficient and secured also helps to improve work culture. (India, 2017).

As per fintech weekly, fintech is a kind of software which enables modern and automated financial services which high security, fintech majorly started in 1990 when importance for internet and e-commerce raised. Because of customers' expectations fintech companies are forced to render services which can be implemented in long run. Fintech companies

*Corresponding author: dakshatanair@gmail.com 
Table 1

Table title comes here

\begin{tabular}{|c|c|c|c|c|c|}
\hline & Money transfer \& payments & Financial planning & Savings and investment & Borrowings & Insurance \\
\hline India & $72 \%$ & $20 \%$ & $39 \%$ & $20 \%$ & $47 \%$ \\
\hline Global & $50 \%$ & $10 \%$ & $20 \%$ & $10 \%$ & $24 \%$ \\
\hline
\end{tabular}

Source: Adoption of Fintech (Priya \& Anusha, 2019)

launched crowdfunding to main direct relationship with customers. Fintech companies also plays important role in insurance industry (InsureTech) which includes everything related to policies, data polices and etc. Robo-advising helps in asset management which provides recommendations to customers which doesn't require human supervision. (Fintechweekly, 2020).

According to Matthew Blake, Peter Vanham \& Dustin Hughes, Fintech is a wider concept which use technology to plan and delivery the financial products to customers as per their choice and convenience. Old-style financial companies \& start-ups started to use fintech technology. To regulate and to protect the investors interest of customers they have many SEBI (Securities Exchange Board of India), Consumer Financial Protection Bureau, Office of the Comptroller of the Currency, the Financial Industry Regulatory Authority, Federal Deposit Insurance Corp., and etc. (Blake, Vanham, \& Hughes, 2016).

According to Vinod Sharma, fintech is a tool which supports all financial services, he strongly beliefs that all financial services are for human beings. Fintech will automatically manage money for betterment of society. These innovations will increase business opportunities more and more. This is done by lining up all financial businesses to provide best financial services to customers by cutting the cost and expanding more services. It collects the data and provide banking fringes to the people. This results in increase in efficiency, probability, trustworthiness of business. (Sharma, 2016).

According to M. Guruprasad (2020), The Indian banking sector has adopted technical advances to achieve productivity in providing the customers with a wide range of products and services, in particular information technology. The reforms of the 1990s, which led to banking and financial sector growth, privatization, and liberalization in India, brought many changes and challenges. Several private and foreign players entered the Indian market with superior technologies that allowed them to effectively service their customers across multiple channels such as ATMs and online banking. The technical infrastructure has become an integral part of the banking system reform process.

What is FINTECH?

Financial technology widely known as Fintech; this brings all the financial companies to use technology to betterment of services provided by them. this is new emerging technology all over the world. Not only the start-ups even the traditional financial companies started to use fintech technologies. The fintech technologies are most commonly used in banks. Fintech technology is applied in few segments like mobile banking, online banking, transfer of money, one to one transaction, blockchain, wallets etc. (Priya \& Anusha, 2019).

Now a days Fintech is widely adopted by most of the people, whereas India stands in 2nd place to adapt the Fintech.
(Kundariya, 2019) In 2015, Fintech start-up funding was \$3.6 billion whereas in 2018 it stood up at $\$ 39.57$ billion which means it increased at $1000 \%$ within a short span (Gilligan, 2020). The table 1 shows which segment adopt the technology more.

Right groupings of regulations, policies and incentives:

- RBI: UPI, digital payments and many other are highly promoted by RBI, by granting licenses so that they can establish payment banks to provide services.

- Government schemes: Indian government setup many plans like digital India, NPCI (National payments council of India) and etc to enable the technology. They are given many benefits like removal of surcharge, tax and etc. to promote Fintech.

- Fintech start-up sector: Greatest incentive taken to expand Fintech business in India, granting permission led to establishment of 125 Fintech companies in 2018 itself. These fintech companies are funded by national $\&$ international banks and by investment groups. (Cyrill, 2018).

What motivates to adopt Fintech?

- Can be used by anyone all over the world.

- Cost effective \& highly secured.

- Boast economic growth along with increase in jobs.

- Conversion of big data into meaningful data.

- Improves traditional approach \& Generates Financial Enclosure (Axios, 2019).

- 24/7 facility, good experience \& functionality (Priya \& Anusha, 2019)

What stops from adopting?

- Security issues (cybercrime)

- Big data (sorting unstructured data collected)

- Disturbance in financial technology application (Accenture, 2018).

- Lack of awareness on usage \& trust on technology

- Trust traditional methods (Priya \& Anusha, 2019)

- Difficult to retain customers \& AI usage (Kundariya, 2019)

What helps to gain high customer experience?

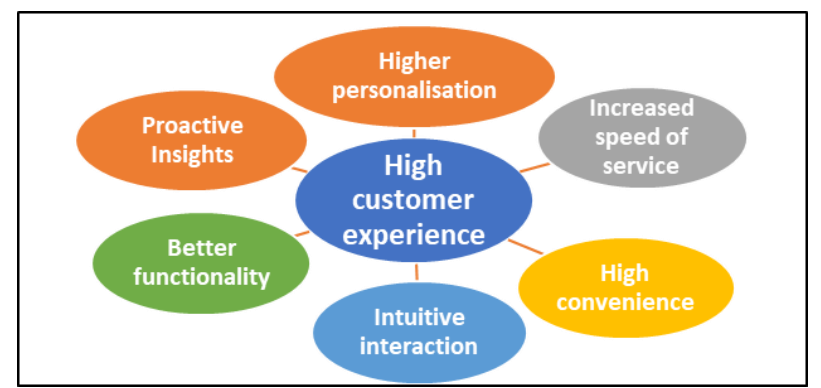

Fig. 1. What helps to gain high customer experience? Source: crested by author (Priya \& Anusha, 2019) 
- Higher personalisation: Having huge data can help to provide personalised services as per customers' requirements.

- Increased speed of service: now-a-days each and every customer wants their work to be done quickly. So, these applications will lead to increase in speed of transactions without turning off the customers.

- High convenience: $24 / 7$ facility is provided and can be operated anywhere.

- Intuitive Interaction: This a method used to guide the customers how to use through designed based technology.

- Better functionality: When pain points of the customers are provided with innovative solutions by Fintech companies then only one can say that they are working better.

- Proactive Insights: Predictive analysis is used to know the customer needs and provide services to it, which helps customers to prevent fraud. (Priya \& Anusha, 2019).

Industrial segments under Fintech:

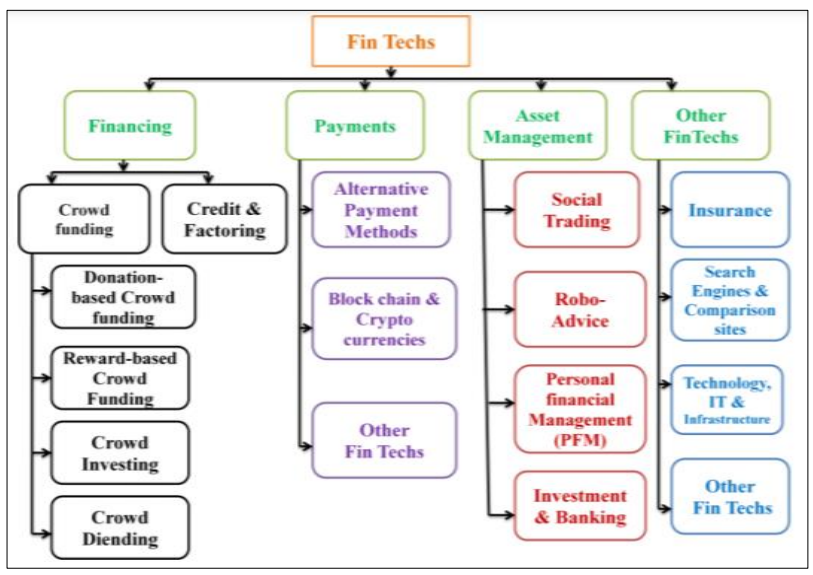

Fig. 2. Industrial segments under Fintech

Source: Fintech industrial segments (Priya \& Anusha, 2019)

- Financing: Using Fintech loans can be taken in two ways. They are crowd funding and credit \& factoring

$>$ Crowd funding: Donation based crowd funding is used charities, reward-based crowd funding is a kind of funding small business which allows investors to invest non-financial benefits. Large set of people will come together and invest in a business through online is crowd investing. Crowd lending means helping both private people and businesses to get loan from public. Here the power lies in both the hands (lender and receiver)

$>$ Credit \& factoring: Factoring means an option to lend the loans. Here with a simple click, businesses can avail loan facility to carry-out the business operations and lenders will get amount very easily in their accounts.

- Payments: Payments means sending money from one to another. Fintech companies allows companies to transfer amount with low cost and effectively.

$>$ Alternative fintech method: Initially amount can be transferred only through banking applications. When Fintech companies came into existence then they created an application where amount can be transferred without banks involvement. Now-a-days few companies are allowing to transfer amount using social media.

$>$ Blockchain and crypto currency: Now a day block chain is used to track one's digital transactions and their asset movement. Even the security which is the major concern has been resolved.

- Asset management: Here investment and financial advice are given to the individuals whose net worth is high. One can contact any wealth mangers to seek advice. This can be done through:

$>$ Social trading: Different parts of people are clubbed together and allows them to share their view points and discuss on it using social hubs. Investors can use this data to make decisions regarding where to invest and all.

$>$ Robo advice: A new software where all necessary data is programmed. If an investor can't effort the advisor then they can use this Robo advisor.

$>$ Personal financial management: This is a software which helps in preparation of budget. To do this the organisation or software requires to collect amount received, expenses and all other necessary information.

> Investment banking: Use of automation in today's world has a greater impact. Fintech companies changed traditional banking methods with low cost. They have their own set of targets.

- Other fintech's: Not only the traditional banking services Fintech companies also providing many other services like payments, financing and management of asset which includes insurance, search engine and etc.

Opportunities for fintech:

- Many start-ups are being benefited by the government policies and the regulations framed or giving by the RBI.

- Increase in digital money value like crypto currency, bitcoins and etc.

- Modernisation will lead to increase in customers, provide better services in less time. (Vijai, 2019).

- Technology innovations and advancements has greater impact on individual's life.

- Machine learning importance will increase in time, which allows people to assess the risk and cybercrime. So, it will always dominate Fintech.

- The traditional business may tie-up with the new startups to develop technology, if they failed to innovate and change as per technology changes to survive in this competitive world.

- Technological development is not done just for the cost reduction but also to complete the task. Even now most 
of task has to be performed manually. so, they have to develop the technology which compliance regulation to do work fast along with cost reduction. (Gilligan, 2020).

- Remote working can lead to increase in productivity of the employees by maintaining their work life balance, by adopting new normal. Fintech companies need to connect with individuals to attract customers via different channels.

- One of the biggest opportunities was caused due to increase in the usage of smartphones, people also started to work from home along with this government also discouraging people to use cash. Because of above mentioned reasons Fintech companies witnessed hike in use of mobile banking and internet banking.

- Customers were attracted by providing them extra services like offering them free investment advices, free services and etc. (Agarwal, 2020)

Challenges faced by Fintech companies:

- Fintech companies will have lot of data which needed to be secured, use of internet will lead to increase in data transmission. There is privacy concern that data can be hacked. So, fintech companies needs to have highly secured security systems.

- Fintech companies are highly exposed to risk because they carry most sensitive information. So, they have to follow the rules and regulations given by General Data Protection Regulation.

- Funding the Fintech start-ups is not an easy task and there is no guarantee that companies will survive. The Fintech companies need to be highly cautions to avoid losses.

- Fintech companies need to change the business models which include revenue and expenditure models as per the change in environment then only the organisation survive. (Agarwal, 2020)

- Initially the fintech companies find difficult to reach the growth stage in life cycle of business. Business collaboration rate is too low. Development of digital money is also low. There is no transparency in business even hiring key tech persons is also difficult task. (Vijai, 2019).

Fintech sectors:

The following are the five many sectors of Fintech. They are

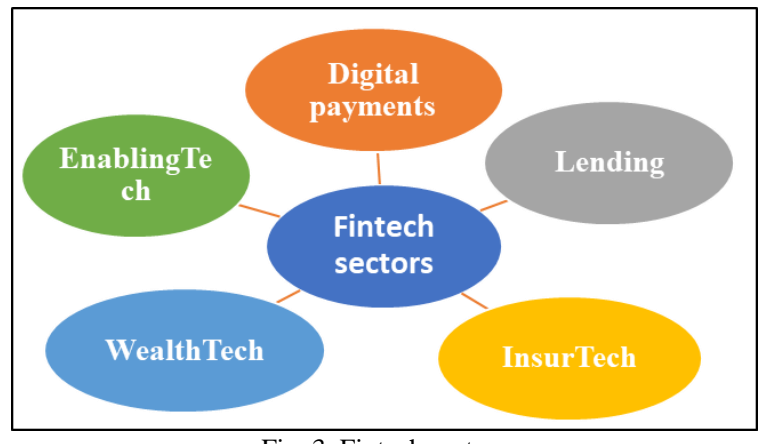

Fig. 3. Fintech sectors Source: Fintech sectors (Belgavi, 2020)
- Digital Payments: In India, the mostly digital payments are mostly funded. Wherein 2019 , just digital payments funding was $\$ 1.9$ billion out of $\$ 3.7$ billion funding in India.

$\checkmark$ Market opportunity: Digital payments transactions in India are expected grow from $\$ 64.8$ billion to $\$ 135.2$ billion by 2023. UPI is also a plus point for digital payment development, whereas its touched \$29 billion by February 2020.

$\checkmark$ Differentiator strategy: Many start-ups are competition with each other by providing new innovative products to differentiate itself from other. A few strategies that are used by fintech companies to differentiate are,

i) Infrastructure provider: Technologies like mobile point of sale $(\mathrm{mPoS})$ or quick response $(\mathrm{QR})$ code are used to transfer money easily into the merchants account via digital payment methods.

ii) Payment gateway + value add: along with the payment options most of the companies are giving services like cash management and banking services to SME customers.

iii) FS wrapped around non-FS business offering: Start-up along with financial services they are offering non-financial services like balance enquiry, information about loans, e-commerce and etc.

iv) Innovative payment devices: Innovative methods to payment using voice without clicking or entering the data. Paytm came up with technology where amount can be transferred without internet. (Belgavi, 2020)

- Lending: lending is divided into two main categories. They are retail lending and MSME lending. Here data is collected with the help of AI for profiling and underwriting the underserved and untapped segment groups to fulfil their credit needs. In India, 30\% of GDP was contributed by MSME lending.

- Retail lending: this sector was designed to engage, profile and underwrite the customers who are notso-credit worthy, new to credit or sub-prime. These businesses force the investors to invest in new emerging business models to segregate the customers as per their needs and classes.

$\checkmark$ Market opportunity: As per the reports giving by Indian analytics company and Indian lending private companies by 2024 , the retail lending in India would be doubled to $\$ 1.24$ trillion.

$\checkmark$ Differentiator strategy: the few strategies used by retail lending companies are,

i) Acquiring customers through point of sale (PoS).

ii) Acquiring customers through an organization.

iii) Direct customer acquisition 
* MSME lending:

iv) Digital lending marketplace.

$\checkmark$ Market opportunity: Even though a greatest contributor to India's GDP. The MSME companies take nearly $40 \%$ of credit from informal sectors. So fintech companies has an opportunity to provide credit to them in formalised way.

$\checkmark$ Differentiator strategy: The few strategies adopted by Fintech companies to lend MSME are,

i) Tech-driven acquisition and underwriting

ii) Invoice financing

iii) FS wrapped around non-FS business offering.

iv) PoS-based lending. (Belgavi, 2020)

- InsurTech: Penetration of Insurance in India was quite less than other penetration around the world. So, many fintech companies came-up with new business models to attract Uninsured category.

$\checkmark$ Market opportunity: Insurance in India is expected to grow by $\$ 220$ billion by 2020 . Increase in private players, innovative products \& channels will lead to growth in insurance sectors. Long with products promotional campaigns are running to teach the importance of insurance.

$\checkmark$ Differentiator strategy: The following are the strategies used by the Fintech companies are,

i) Digital convenience: Now-a-days, most of insurance companies came up with digital products where they can differentiate the products, can purchase the polices along with settlements, offering superior customer experience.

ii) Niche products: targeting new customers with new age products based on the requirements and the situations.

iii) Web aggregators: Technology is being employed by start-ups to provide a wide variety of best-suited customers with options by marketplaces and digital simplification buying. (Belgavi, 2020)

- WealthTech: WealthTech is categorized as providing products and services ranging from apps for financial services, investing networks, tools for online investment and Robo-advisors to automated brokerages. In order to transform conventional investment and wealth management services, WealthTech players use innovative technologies such as AI and analytics too.

$\checkmark$ Market opportunity: Wealth management is highly underrated in India. So, the fintech companies have handful-off opportunities to start advisory, brokerage firms to become a full-stacked operator. It was predicted that Robo-advisory market size in India be $\$ 145$ million by 2023 .

$\checkmark$ Differentiator strategy: following are the strategies used by WealthTech companies are, i) Digital discount brokers: Fintech companies firstly need to improve technology so that they can offer better services to the customers with low cost or giving them best discount.

ii) Digital wealth platforms: These start-ups are providing services like 3600 view about the investments made by the clients. These companies will stand in shoes of the customers and advise them.

iii) Robo-advisory: Now-a-days, the fintech companies are giving advices to the clients with minimal human involvement (AI chatbot). (Belgavi, 2020)

EnablingTech: This is a strategy which provides solutions to both traditional financial institutions and new fintech companies and helps them to design, develop and innovative products to the customers. The following are the case where Fintech used EnablingTech are,

$\checkmark$ Agent productivity: This technology is used as an agent which provides seamless distribution of products and services to the clients.

$\checkmark$ E-KYC, fraud and compliance: Technologies like AI, biometric helps fintech companies and banks to provide advanced solutions for securing transactions, preventing from money-laundering and etc.

$\checkmark$ Account aggregation: This method entails the mining, assortment and examination of data from multiple outlets, such as loan/payment records, bank accounts, credit and debit cards and investment accounts, and supplementary business or consumer accounts such as e-commerce, food or mobility accounts.

$\checkmark$ Customer acquisition and service: Robo-advisory and chatbots are also a part of EnablingTech. These technologies are either fully or partially automated to attract customers and retain them over the time. These services are provided at low cost, efficient services. (Belgavi, 2020).

\section{Impact of COVID-19 On Fintech Industry}

The fintech landscape in India has been drastically changing at a lightning speed in the last couple of years and has become one of the world's largest fintech market after US, UK and China. With COVID-19-19 severely disrupting various workflow in various sectors of the country, Fintech sector continues to be one area that has witnessed tremendous amount of volatility in its structure and work due the significant shift on online technology caused by the pandemic. Due to the pandemic, a lot of companies focussed on product and process innovation to become more customer centric and build the capacity to handle large disruptions.

\section{A. Changing landscape of fintech sectors in India due to COVID-19}

\section{1) Payments}

Key Sub segments -

Payment segment in FinTech comprises various sub 
segments like PoS companies, Digital Wallets, Bill Payments, Remittance Firms and Payment Gateways.

Impact of COVID-19:

- Cash Based Transactions are expected to reduce during COVID-19-19, being cash as one of the potential carriers of the disease. In this situation, digital payments may witness an increase rate of adoption.

- Education, online gaming, grocery, utility payments is expected to turn into digital lines, the support of the government with Reserve Bank of India advocating use of digital payments. Due to this reason, Fin Tech companies decided to redesign the user interface to be relevant with essential payments to be online sticking to rules and regulations issued by the government.

- Physical transaction on Merchant outlets also became the victim of the pandemic, with reduction in remittances due to lockdown imposed on migrant and domestic workers.

\section{2) Alternative lending}

Key Sub segments -

The alternative lending segment in FinTech comprises various subsegments such as the FinTechs with NBFC license, distribution platform, supply chain finance, P2P lending, distribution platforms, supply chain finance, PoS lending, Payday lending and SME lending.

\section{Impact of COVID-19:}

- Fintech lenders have developed their company on the premise that consumers income levels are rising and due to their ever-increasing aspirational demands, many blue collars employees have been under the radars of these lenders.

- Sectors like Airline, Food \& Beverage and Ride Hailing services employ significant amount of gig employees who are facing risk of lower wages and inability to pay long term loans.

- COVID-19 has caused a potentially long lasting on MSME Sector with sudden interruption in supply chain and subdued demand have left MSME's in urgent need to generate cash flow.

- With Indian Economy already engulfed in trap of Economic slowdown, COVID-19 -19 could have further impact on MSME lending, with leading Fintech Companies creating larger loan books to lend MSME based on cash flow rather than assets.

\section{3) Wealth tech}

Key Sub segment -

Wealthtech segment in FinTech comprises various sub segments such as digital discount brokers, robo advisors, mutual fund advisors, personal finance management apps, micro investing platforms and foreign investing apps.

Impact of COVID-19:

- Digital wealth management platforms have reported an upsurge in number of new accounts opened and volume of transactions, resulting in entry of new investors in capital markets to take advantage of a sluggish markets.

- With reduction in revenue and assets under management, there has been significant impact on market participants in form of small, consolidated players and increased use of robo advisory.

- WealthTech funding is set to hit a new record of $\$ 3.7$ billion across 157 deals and is set to increase further with increased investments in sustainable investments and API integration serving as catalyst for wealth tech funding throughout 2021.

\section{4) Insuretech}

Key Subsegments -

The Insuretech segment in Fintech comprises various subsegments like digital insurance manufacturers, distribution platforms and web aggregators.

Impact of COVID-19:

- The outbreak of the pandemic has witnessed a growth of increase in insurance premium among non-life insurance segment, with increase in demand for insurance products remaining volatile.

- With Travel industry severely hit by the pandemic there has been decline for travel and vehicle insurance, with sector witnessing increasing demand for health insurance policies.

- Digital Insurance companies like Acko, Artivatic, Policy Bazaar etc. have seen surge in the demand of their products as the companies devoted itself in offering seamless purchase, disbursement and claiming services with minimal interaction at competitive pricing.

- Digitalisation drastically helped insurers especially life and health - to create and distribute simplified, digital-native solutions in a costeffective manner.

\section{5) Neobanks}

Key Sub segments -

The neobank segment in FinTech comprises neobanks that serve retail customers and ones that serve business customers, primarily Small Medium Enterprises.

\section{Impact of COVID-19:}

- With discretionary costs being reduced and ongoing programmes kept on hold, Neobanks are facing problems to attract deposits and keeping it afloat although it is useful to provide value added services CASA accounting and expense management.

- In Post COVID-19 world, digital banks are expected to attract more customers and Small Medium Enterprises looking to avail better banking experience from digital channels in a simple, secure, and cost-effective manner.

- Due to their innovative business models and digital payments channels, Neobanks have been widely adopted globally due to swift transition to work from home model resulting in growth of digital financial services. 


\section{6) Emerging tech}

Key Sub segments -

The emerging tech segment in FinTech comprises software like SaaS based technology providers, B2C FinTechs which offer digital onboarding, chatbots, Customer Relation Management, API Platforms, and productivity tools.

Impact of COVID-19 on Emerging Tech:

- With a greater number of online options, Fintech enablers could offer cloud-based solutions that will could experience higher demand from service providers.

- $\mathrm{AI}$ is expected to be the most demanded technology for products and services like conversation solutions for call centre chatbots, fraud detection and workflow automation.

- Digital identity providers (IDaaS) are also expected to be in demand as KYC processes to be digitalised further.

\section{Tackling in Post Covid Scenario:}

The COVID-19 had drastic impact on economy in every aspect. It has not only changed how Foreign Investors operates their business but also how the management performs its tasks and how people across the globe monitor their finances. Every sector had seen changes in their working pattern, focusing on Financial Sector it has been noticed that role of digital platforms, products and services is rising.

A digital-native company is digitalized and advanced.

Its activities and advancements at a speed that is significantly greater than that of conventional firms. The common denominator of most FinTech disruptors is that, along with streamlined processes, they leverage new technology and its applications to create scalable and sustainable business models.

Digital native companies use their inherent advantage to ensure a seamless transition for staff and continuity of operations as remote work becomes the norm. Companies need a combination of scalable on demand infrastructure remotely accessible software, digital communication methodologies and a responsive culture to allow a smooth transition to remote operations to ensure a swift and decisive response to crisis.

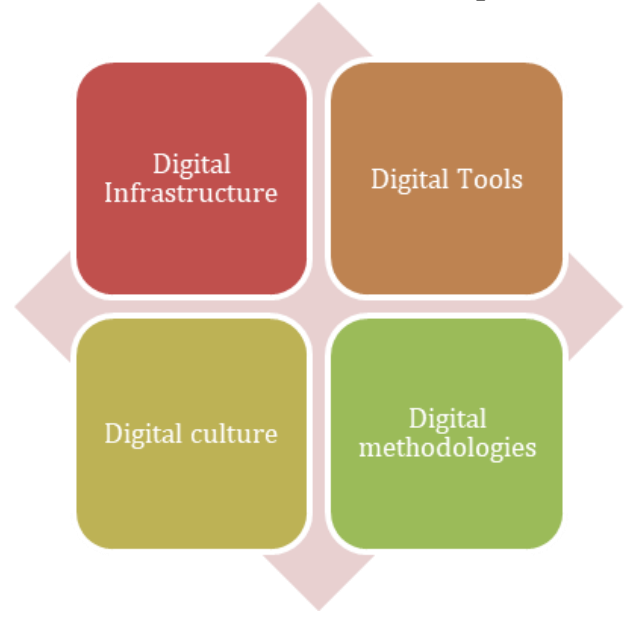

Fig. 4. Digital structure Source: Created by author

Access to protected data methodology and balancing privacy and cyber threat requirements together with a digital environment will play key roles to ensure smooth operations and decision making. Below is a digital structure that defines the main business components in the post COVID-19 period to keep them functional.

- Digital Infrastructure: scalable technology on demand with safe connectivity to enable digital transformations and secure movement of information when operating remotely.

- Digital Tools: business application and interaction tools that allows remote communication and collaboration are employee facing.

- Digital Culture: workplace policies to encourage remote work, flexible working hours and initiatives to work.

- Digital Methodologies: to predict and adapt quickly to new needs to develop innovation centres and omni channel.

Table 2

Trending technologies in banking

\begin{tabular}{|l|l|l|l|l|}
\hline & $\begin{array}{c}\text { Already } \\
\text { Deployed }\end{array}$ & $\begin{array}{c}\text { Plan to } \\
\text { invest in } \\
\mathbf{2 0 1 9}\end{array}$ & $\begin{array}{c}\text { Executing } \\
\text { team is } \\
\text { discussing }\end{array}$ & $\begin{array}{l}\text { Not on } \\
\text { Radar }\end{array}$ \\
\hline $\begin{array}{l}\text { Machine } \\
\text { Learnings }\end{array}$ & $2 \%$ & $12 \%$ & $35 \%$ & $51 \%$ \\
\hline Chatbots & $2 \%$ & $13 \%$ & $45 \%$ & $40 \%$ \\
\hline $\begin{array}{l}\text { Robotic Process } \\
\text { Automation } \\
\text { RPA) }\end{array}$ & $5 \%$ & $6 \%$ & $31 \%$ & $58 \%$ \\
\hline Block chains & $1 \%$ & $4 \%$ & $43 \%$ & $52 \%$ \\
\hline $\begin{array}{l}\text { Cornerstone Advisors survey of 305 mid-size banks and credit } \\
\text { unions, Q4 2018 }\end{array}$ \\
\hline
\end{tabular}

\section{Strategies to Overcome COVID-19 Challenges}

Digital financial service can thrive in a situation where customers are forced to accept or use online platforms to digitize the exposure to health hazards. Fintech tactics will be at the level at which the value of delivering such services directly to end-consumers or looking at possibilities for collaborations with larger groups of people. Also for FinTech business models a move towards non-physical platforms such as contactless payments, digital onboardings, credit assessment and payment processing may become significant help.

Fin-techs have digitalized in historically undeserved markets for catering in current situation this is important especially when government attempts to allocate benefits to those most vulnerable areas, fintech may investigate such places to diversify their business model and services.

During these times business models that can offer or spread the awareness of safe and healthy offerings can have an edge over others. Fintech companies can take a hint or clue from market leaders of food delivery channel those who are focusing on safety concerns of customers so to keep the users active.

Fintech would need to look inward at their ways of operating while being able to simplify and digitize customer experience. Remote working will require joint investment, infrastructure for data and security to promote business. Tech players will find potential buyers to boost and assist in internal efficiency.

Fintech responds quickly to economic challenges and 
develop creative consumer goods and services. It was born after global financial crisis of 2008, it provides financial services with the consumption of critical services

It could also expand the exposure of portfolio to essential services which includes lending, wealth management portfolios or business to business partnerships.

\section{Strategic Recommendations:}

\section{A. Cost reduction and stable cash flow}

- Provide incentives to customers to motivate them to pay in advance.

- Set targets for receivables.

- Reconstruct and negotiate contracts which are benefitted in long term with vendors and landlords.

\section{B. Asset Management}

- Considering the obstacles of COVID-19 promote more work from home culture and to maintain social distancing.

- Crucial decisions need to be taken after taking each aspect into consideration rather it be hiring the work force or giving salaries to them.

- Bring in innovative ideas and provide training to workforce so that there is smooth functioning and productivity is increased.

\section{Revaluate business models}

- Consumers perspective plays important part in creating new business model according to how a new normal culture will look like.

- Strategic planning for new product launches in diversified channels.

\section{Conclusion}

It is also wise to consider the steps and measures used by other countries to handle the crisis. These initiatives have been summarised concentrating on measures that support fin tech industry. Interventions have been grouped into following categories:

- Relief Policy: policy makers and regulators have targeted initiatives and stimulus programmes that directly strengthens the fintech eco system.

- Forbearance Policy: directives given to financial investors by government and regulatory bodies for indirect benefits of end users.

The state government and regulatory bodies have implemented strategies that have been successful in past and also followed by other countries mentioning few liquidity measures through monetary policy, employee retention programmes, promoting lending to small and medium enterprises sector. Some of the additional areas are highlighted below:

- The governments approach for providing credit guarantees for loans to NBFCs to a certain extent could help to alleviate the risk aversion of banks and provide funds to small business and encourage them.

- Using fin-tech to spread financial incentives.

- Provide funds to fin tech specific start-ups so that they can contribute more.

\section{References}

[1] Accenture. (2018). Mind The Gap: Addressing Challenges to Fintech Adoption. New York: Accenture, Fintech Innovation Lab.

[2] Agarwal, H. (2020, July 22). New Challenges and Opportunities for FinTech Companies Post COVID-19. Retrieved from Beaconstac: https://blog.beaconstac.com/2020/05/fintech-companies-post-covid/

[3] Axios. (2019, September 23). 6+ REASONS WHY FINTECH IS IMPORTANT. Retrieved from Axios: https://axiosholding.com/6reasons-why-fintech-is-important/

[4] Belgavi, V. (2020). Redefining the FinTech experience: Impact of COVID-19. India: PWC.

[5] Blake, M., Vanham, P., \& Hughes, D. (2016). 5 things you need to know about fintech. Cologny: World Economic forum. Retrieved from https://www.weforum.org/agenda/2016/04/5-things-you-need-to-knowabout-fintech/

[6] Cyrill, M. (2018, November 27). Future of Fintech in India Opportunities and Challenges. Retrieved from India Briefing: https://www.india-briefing.com/news/future-fintech-india-opportunitieschallenges-12477.html/

[7] Fintechweekly. (2020). FINTECH DEFINITION. Köln, NordrheinWestfalen, Germany.: Fintechweekly. Retrieved from https://www.fintechweekly.com/fintechdefinition\#: :text=FinTech\%20Definition,way\%20we\%20manage\%20o ur\%20finances.

[8] Gilligan, J. (2020, January 9). The Fintech Revolution-opportunities and challenges in 2020. Retrieved from Agility Pr solutions: https://www.agilitypr.com/pr-news/public-relations/the-fintechrevolution-opportunities-and-challenges-in-2020/

[9] India, D. (2017). FinTech in India, Ready for breakout. IAMAI.

[10] Kundariya, H. (2019, December 9). The Challenges of Fintech Application in Modern Era - A Comprehensive Guide. Retrieved from Customer Think: https://customerthink.com/the-challenges-of-fintechapplication-in-modern-era-a-comprehensive-guide/

[11] Priya, P. K., and Anusha, K. (2019, September). Fintech Issues and Challenges in India. International Journal of Recent Technology and Engineering, 8 (3), 904 - 908.

[12] Sharma, V. (2016). What is FinTech and where does it Live? London, UK: Finextra. Retrieved from https://www.finextra.com/blogposting/12890/what-is-fintech-andwhere-does-it-live

[13] Thakor, A. V. (2019). Fintech and banking: What do we know? Journal of Financial Intermediation, 1 - 13

[14] Vijai, D. C. (2019, January). Fintech in India - Opportunities and Challenges. South Asian Academic Research Journals, 8 (1), 42-54.

[15] M. Guruprasad, Information Technology in Indian Banking Sector, Tathapi, 2020

[16] M. Guruprasad, Evolution of Technology in the Banking Sector, 2018. 